\title{
Perancangan Aplikasi Notifikasi Pembuatan Baglog Jamur Tiram
}

\author{
Engineering of Notification Application for Oyster Mushroom Baglog Making
}

\author{
I Gusti Ayu Desi Saryanti \\ Sistem Informasi, STIKOM Bali \\ Jl. Raya Puputan No.86 Renon Denpasar, 0361244445 \\ e-mail : desi@stikom-bali.ac.id
}

\begin{abstract}
Abstrak
Jamur merupakan salah satu jenis makanan yang bergizi bagi manusia. Jamur tiram merupakan salah satu sumber makanan yang setara dengan daging, baik kelezatan maupun kandungan gizinya. Baglog adalah Media tanam jamur yang digunakan sebagai bahan produksi jamur tiram, namun karena informasi pembuatan baglog jamur tiram masih tergolong belum terlalu banyak dan tidak lengkap sehingga banyak pembudidaya jamur tiram yang belum memahami dengan benar cara pembuatan baglog jamur tiram. Dengan melakukan observasi, study literatur, analisis data, dan perancangan sistem, maka dibuat aplikasi notifikasi pembuatan baglog jamur tiram yang diharapkan dapat membantu dan memberikan informasi tentang pembuatan baglog jamur tiram yang benar kepada para pembudidaya jamur dalam melakukan kegiatan budidaya. Perancangan aplikasi ini dapat membantu pengembang aplikasi dalam memberikan informasi dan mempermudah para pembudidaya jamur tiram dalam proses pembuatan baglog jamur tiram
\end{abstract}

Kata kunci: Jamur, Baglog, Unified Modeling Language

\begin{abstract}
Mushroom is one kind of food that is nutritious for humans. The oyster mushroom is one source of food that is equivalent to meat, or deliciousness and nutritional content. Baglog is a mushroom growing media that used as oyster mushroom production, but because of the manufacture information baglog oyster mushrooms that are not too much and did not complete so many oyster mushroom farmers who don't understand exactly how to make baglog oyster mushrooms. By observation, literature study, data analysis, and system design, so this design a notification application made of baglog manufacture of oyster mushrooms that expected to assist and provide information about making the right baglog oyster mushroom to mushroom growers in conducting farming activities. The design of this application can help application developers to provide information and facilitate the oyster mushroom growers in the manufacturing process baglog oyster mushrooms.
\end{abstract}

Keywords: mushroom, Baglog, Unified Modeling Language

\section{PENDAHULUAN}

Penggunaan teknologi oleh manusia kini berkembang sangat pesat. Banyak teknologi baru yang diciptakan manusia untuk memudahkan keperluan mereka. Contohnya saja teknologi pertanian, teknologi internet, dan masih banyak teknologi lainnya. Teknologi informasi dan komunikasi mempermudah kehidupan manusia. Jika menggunakan alat teknologi informasi dan komunikasi, dua benua akan terasa tidak berjarak. Kehadiran komputer, internet, telepon seluler, dan berbagai alat teknologi informasi dan komunikasi membuat arus informasi semakin lancer. Namun, teknologi jaman sekarang masih terus berkembang pesat dan menciptakan inovasi dan karya-karya terbaru. Salah satunya adalah teknologi Smartphone yang menjadi fenomena pada 
saat ini. Smartphone menjadi fenomena karena beberapa kelebihan yang dimilikinya daripada handphone lainnya. Oleh karena itu juga, smartphone disebut sebagai teknologi baru.Bagi kehidupan manusia jamur tiram terasa sudah tidak asing lagi. Jamur tiram atau Pleurotus ostreatus merupakan jamur yang dapat dikonsumsi dan memiliki ciri-ciri umum, yaitu tubuh buah yang berwarna putih hingga krem, serta memiliki tudung yang berbentuk lingkaran mirip dengan cangkang tiram. Bahkan jamur tiram menjadi sumber makanan yang setara dengan daging, baik kelezatan maupun kandungan gizinya. Sadar akan potensi jamur tiram sebagai bahan makanan bergizi, pengadaannya tidak mengandalkan hasil 'buruan' dari alam, melainkan dari budidaya jamur tiram yang serius dan perdagangan antar negara. Nilainya cukup tinggi, dari ribuan sampai jutaan rupiah perkilogramnya. Didasari pada kebutuhan untuk mempermudah kegiatan budidaya jamur tiram pada setiap perusahaan maka sangatlah penting untuk membuat sebuah aplikasi notifikasi pembuatan baglog. Baglog adalah Media tanam jamur tiram yang digunakan sebagai bahan produksi jamur tiram. Pada media ini nantinya akan dikondisikan agar tumbuh jamur tiram. Istilah baglog mengandung arti kantung (bag) media berbentuk kayu gelondongan (log). Ketika plastik media dilubangi atau sobek, dari lubang itulah akan tumbuh jamur. Dengan adanya perancangan aplikasi ini diharapkan dapat membantu pengembang aplikasi dalam mempermudah dan mengefisienkan kegiatan pembuatan baglog dalam budidaya jamur tiram serta memaksimalan kualitas pertumbuhan jamur tiram.

\section{METODE PENELITIAN}

\subsection{Metode Pengumpulan Data}

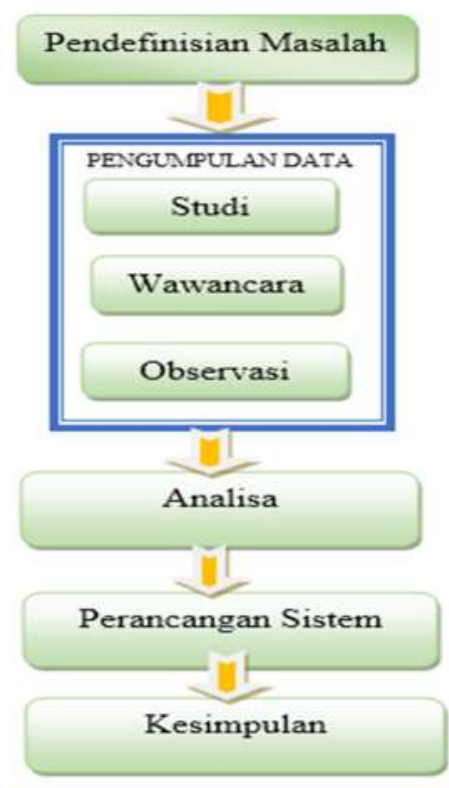

Gambar 1 Alur Analisis

Penelitian ini diawali dengan pengumpulan data dan dilanjutkan dengan penerapan dari metode yang digunakan. Tahapan kegiatan secara rinci dari penelitian yang dilakukan adalah sebagai berikut:

1. Pendefinisian permasalahan berkaitan dengan perancangan sistem

2. Studi Pustaka, pengumpulan data berupa buku-buku, paper atau dokumentasi yang berkaitan dengan penelitian yang dilakukan.

3. Wawancara, dilakukan proses tanya jawab antara peneliti dengan responden. 
4. Observasi, yaitu pengamatan secara langsung pada proses-proses yang sedang berjalan.

5. Analisa, melakukan proses penganalisaan terhadap permasalahan yang dibahas pada penelitian.

6. Perancangan system, dilakukan dengan melakukan perancangan terhadap pembuatan baglog jamur tiram.

7. Pengambilan kesimpulan.

\subsection{Pengertian Baglog}

Baglog adalah Media tanam jamur yang digunakan sebagai bahan produksi jamur. Pada media ini nantinya akan dikondisikan agar tumbuh jamur. Istilah baglog mengandung arti kantung (bag) media berbentuk kayu gelondongan (log). Ketika plastik media dilubangi atau sobek, dari lubang itulah akan tumbuh jamur. Baglog bisa diperoleh dengan cara membeli yang telah ditanami bibit seqhingga hanya perlu melakukan pemeliharaan hingga badan buah tumbuh. [1]

\subsection{Cara Membuat Baglog}

Mempersiapkan media tanam : persiapan media tanam meliputi formula subtrat, pembasahan awal, pengomposan, dan pengemasan media. Media tanam yang selesai proses pengomposannya di kemas dalam kantong plastik PP. Ukuran kantong dari berat yang di tetapkan, setelah itu media tanam di padatkan mengguanakan alat pengepres atau botol hingga bagian bawah plastik menyerupai log kayu (baglog). Selanjutnya ujung plastik di pasang ring, di tutup dengan kapas, dan di pasang dengan plastik penutup baglog. Setelah itu baglog di sterilisasi pada suhu 90 derajat celcius selama 90 menit. Media tanam yang sudah di sterilisasi di dinginkan hingga suhunya mencapai suhu ruang sekitar 25 derajat celcius, proses pendinginan dapat di lakukan di dalam ruangan yang mempunyai sirkulasi udara yang baik. Setelah baglog dingin proses selanjutnya adalah pemasukan atau pemberian bibit jamur tiram ke dalam baglog jamur. [2]

\subsection{Pengertian Jamur}

Jamur adalah tubuh buah yang tampak di permukaan media tumbuh dari sekelompok fungi (Basidiomycota) yang berbentuk seperti payung: terdiri dari bagian yang tegak ("batang") dan bagian yang mendatar atau membulat. Secara teknis biologis, tubuh buah ini disebut basidium. Beberapa jamur aman dimakan manusia bahkan beberapa dianggap berkhasiat obat, dan beberapa yang lain beracun. Contoh jamur yang bisa dimakan: jamur merang (Volvariela volvacea), jamur tiram (Pleurotus), jamur kuping (Auricularia polytricha), jamur kancing atau champignon (Agaricus campestris), dan jamur shiitake (Lentinus edulis). [3]

\section{HASIL DAN PEMBAHASAN}

\subsection{Use Case Diagram}

Penentuan use case diagram ditentukan dengan proses jalannya sistem dan proses apa saja yang dapat dilakukan oleh user terhadap sistem. Adapun diagram use case dari aplikasi ini adalah sebagai berikut : 


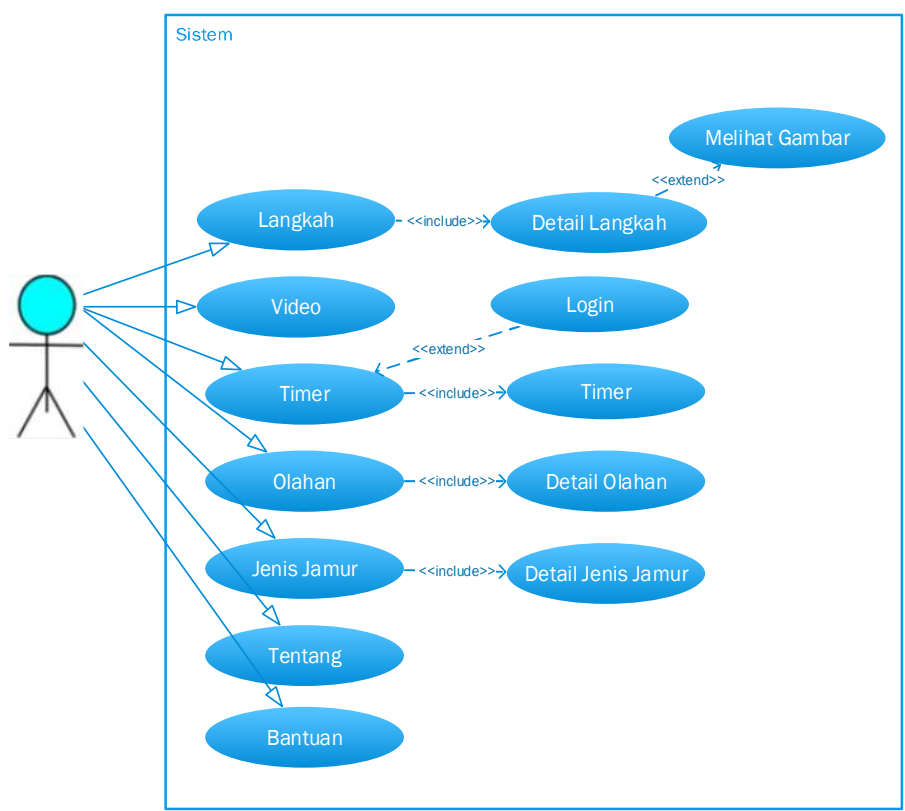

Gambar 2 Use Case Diagram

\subsubsection{Use Case Langkah}

Tabel Expended Use Case diatas merupakan Expended Use Case Menu Langkah dimana menjelaskan pemilihan menu langkah yang di dalamnya terdapat penjelasan detail dari langkah pembuatan baglog.

Tabel 1 Expended Usecase Langkah

\begin{tabular}{|c|c|c|}
\hline Nama Use Case & \multicolumn{2}{|l|}{ Langkah } \\
\hline Aktor Utama & \multicolumn{2}{|l|}{ User } \\
\hline Kondisi Awal & \multicolumn{2}{|c|}{ User mulai menjalankan Aplikasi } \\
\hline Kondisi Akhir & \multicolumn{2}{|c|}{ Sistem menampilkan detail langkah dan gambar } \\
\hline \multirow[t]{4}{*}{ Skenario Sukses } & Aksi Aktor & Aksi Sistem \\
\hline & $\begin{array}{ll}\text { 1. } & \text { User menjalankan } \\
\text { sistem aplikasi } \\
\text { penjadwalan pembuat } \\
\text { baglog } \\
\end{array}$ & $\begin{array}{l}\text { 2. Sistem akan menampilkan } \\
\text { menu utama }\end{array}$ \\
\hline & $\begin{array}{l}\text { 3. User memilih menu } \\
\text { langkah }\end{array}$ & $\begin{array}{l}\text { 4. Sistem menampilkan menu } \\
\text { langkah }\end{array}$ \\
\hline & 5. User memilih langkah & $\begin{array}{l}\text { 6. Sistem menampilkan detail } \\
\text { langkah dan gambar }\end{array}$ \\
\hline
\end{tabular}




\subsubsection{Activity Diagram Langkah}

Activity ini di mulai ketika user menjalankan aplikasi Langkah dimana menjelaskan pemilihan menu langkah yang di dalamnya terdapat penjelasan detail dari langkah pembuatan baglog.

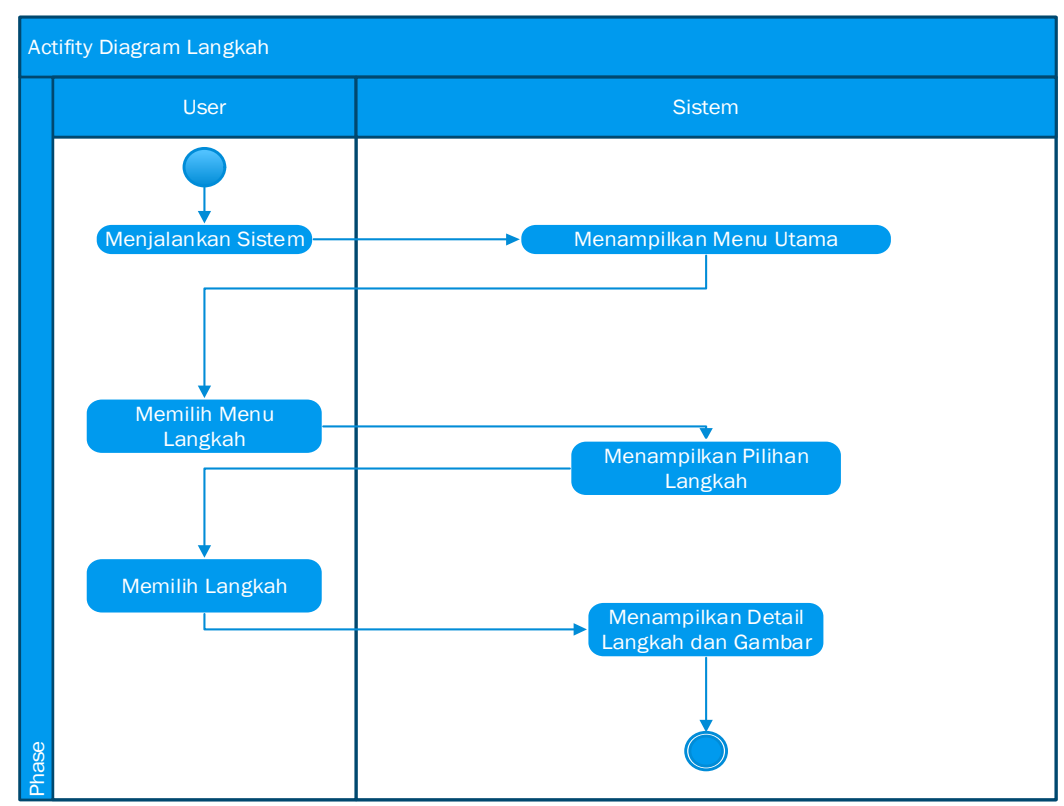

Gambar 3 Activity Diagram Langkah

\subsubsection{Sequence Diagram Langkah}

Gambar 4 merupakan gambaran proses Langkah dimana menjelaskan pemilihan menu langkah yang di dalamnya terdapat penjelasan detail dari langkah pembuatan baglog.

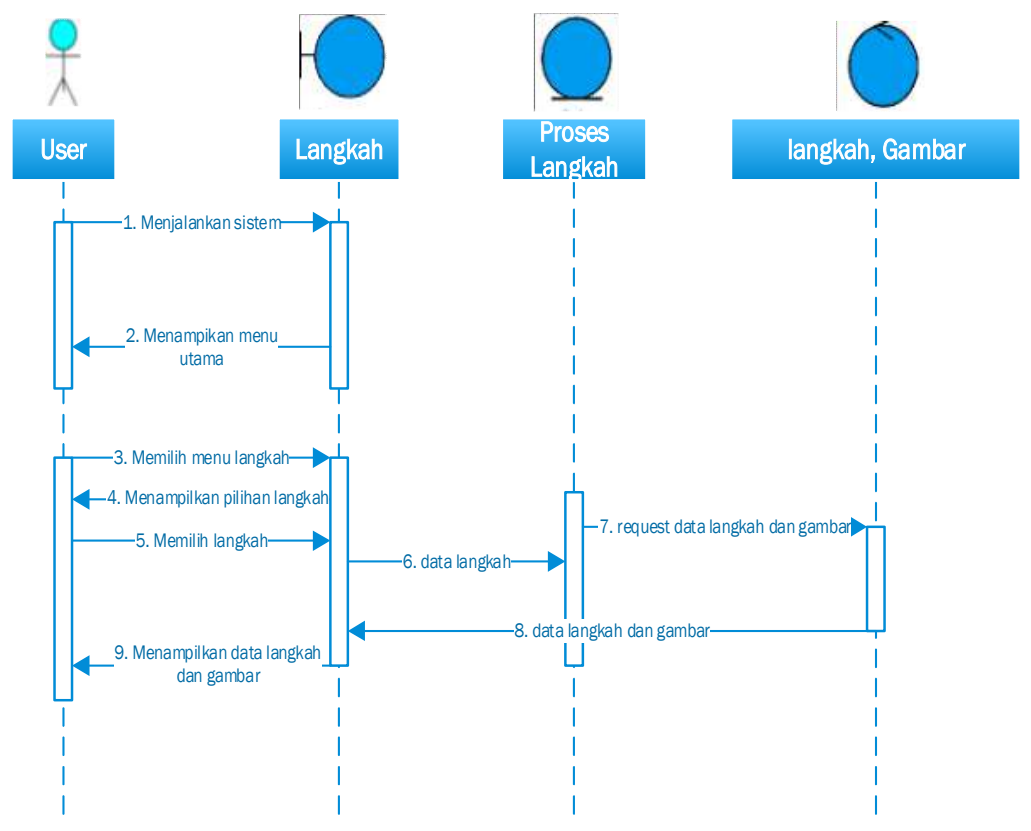

Gambar 4 Sequance Diagram Langkah 


\subsection{Class Diagram}

Class Diagram adalah sebuah spesipikasi yang jika diinstansikan akan menghasilkan sebuah objek dan merupakan inti dari pengembangan dan desain sistem sekaligus menawarkan layanan untuk memanipulasi keadaan tersebut.

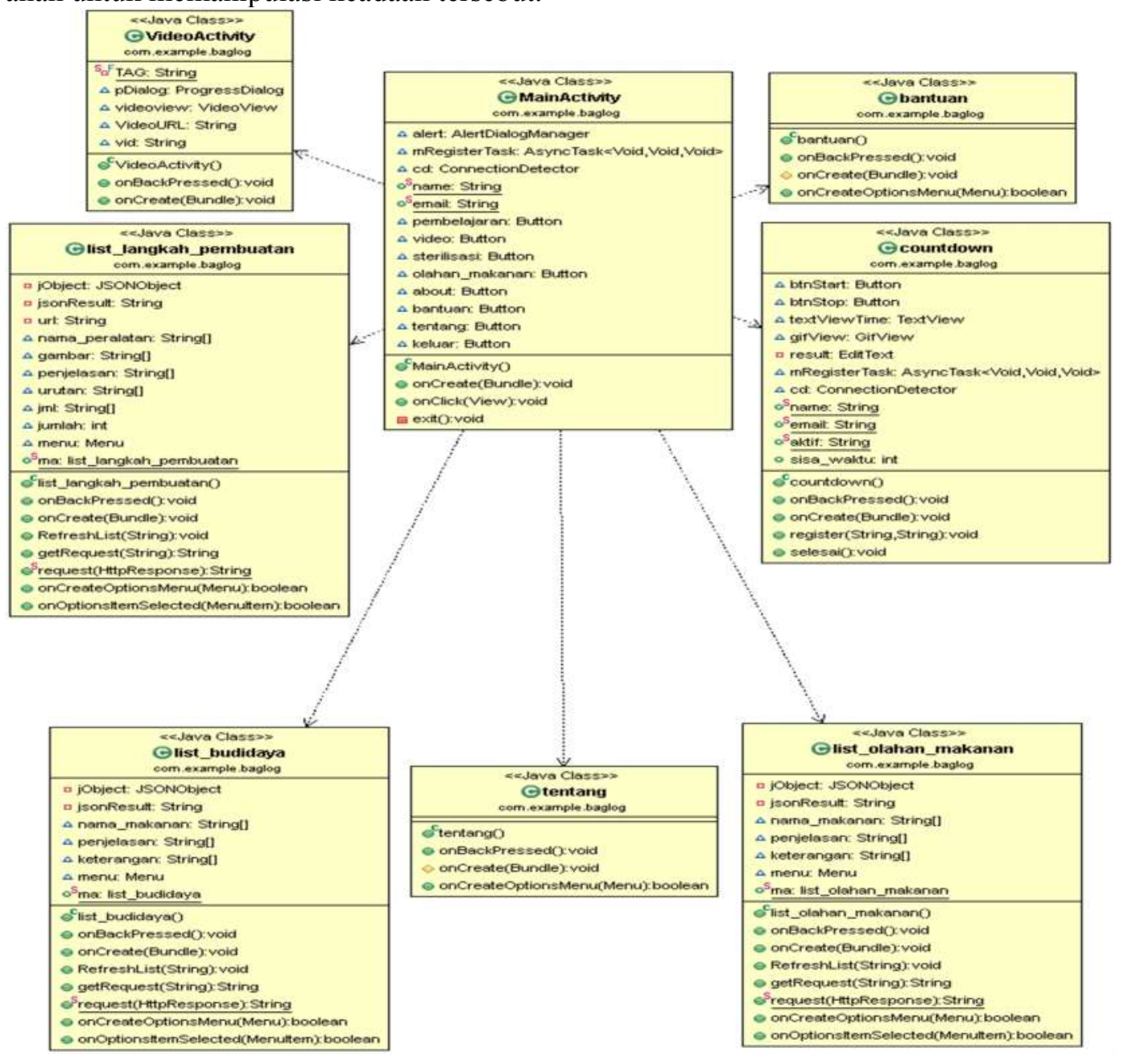

Gambar 5 Class Diagram

\subsection{Entity Relationship Diagram ( ERD )}

ERD merupakan teknik yang digunakan untuk memodelkan kebutuhan data dari suatu organisasi, oleh sistem analis dalam tahapan analisa persyaratan proyek untuk mengembangkan sistem. ERD merupakan model data yang pada gilirannya digunakan sebagai spesipikasi untuk database.

Gambar

Gambar 6 Entity Relationship Diagram

\section{Langkah}




\subsection{Konseptual Database}

Konseptual database merupakan suatu media penyimpanan yang digunakan untuk menyimpan data-data penunjang sebagai inputan sistem dan kemudian diolah menjadi data output system.
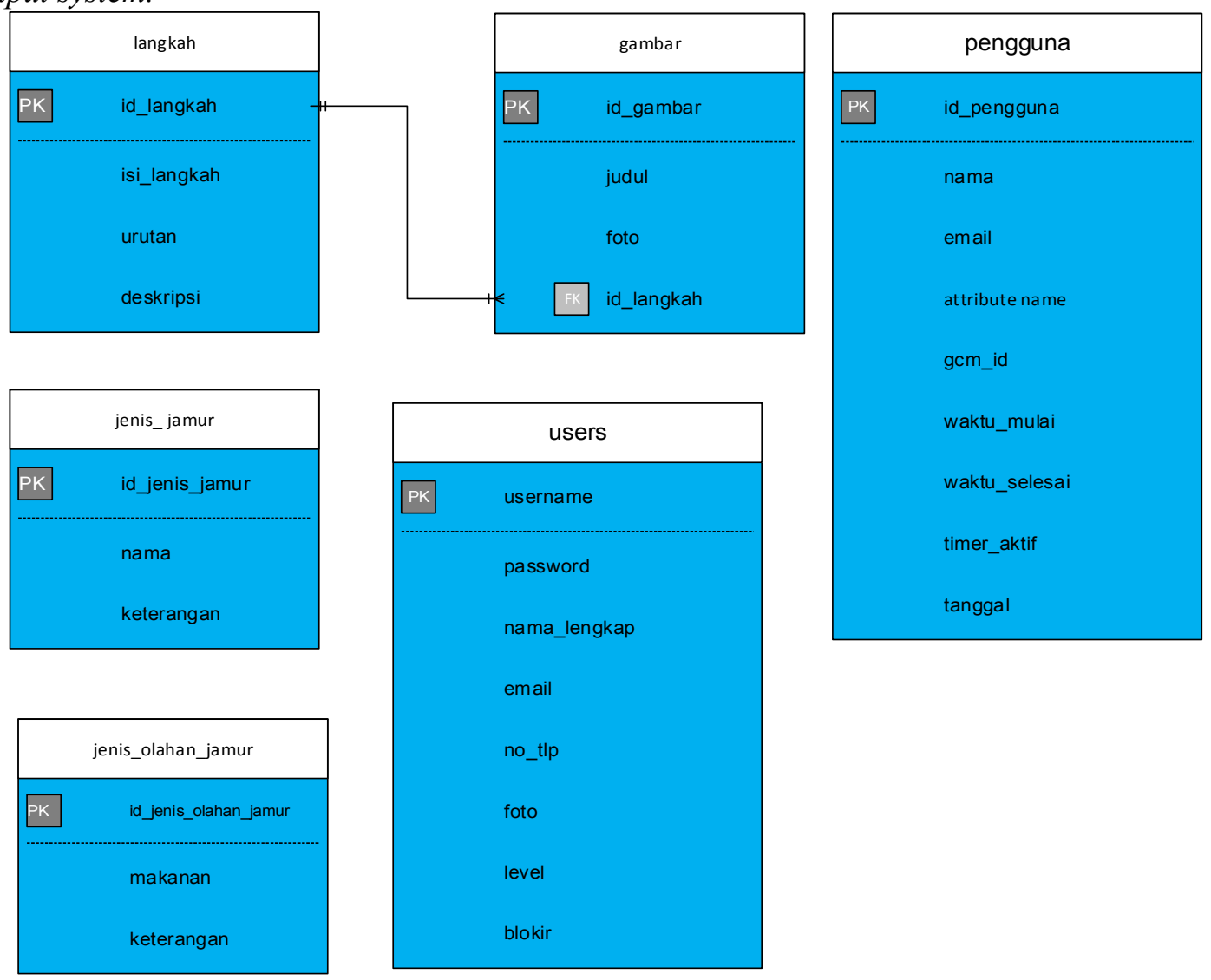

Gambar 7 Konseptual database

Pada gambar diatas menunjukkan bentuk konseptual database dimana setiap tabel memiliki atribut yang berbeda serta memiliki primary key dan juga atribut lainya yang mendukung tabel tersebut.

\subsection{Desain Antar Muka}

Berikut merupakan desain interface yang akan digunakan dalam aplikasi Penjadwalan Pembuatan Baglog Jamur Tiram.

\section{a. Halaman Utama}

Gambar 5.19 merupakan desain antar muka untuk halaman utama dari aplikasi Notifikasi Sterilisasi Pembuatan Baglog Jamur tiram. Pada halaman utama ini menampilkan menu-menu apa saja yang tersedia di form menu utama. 


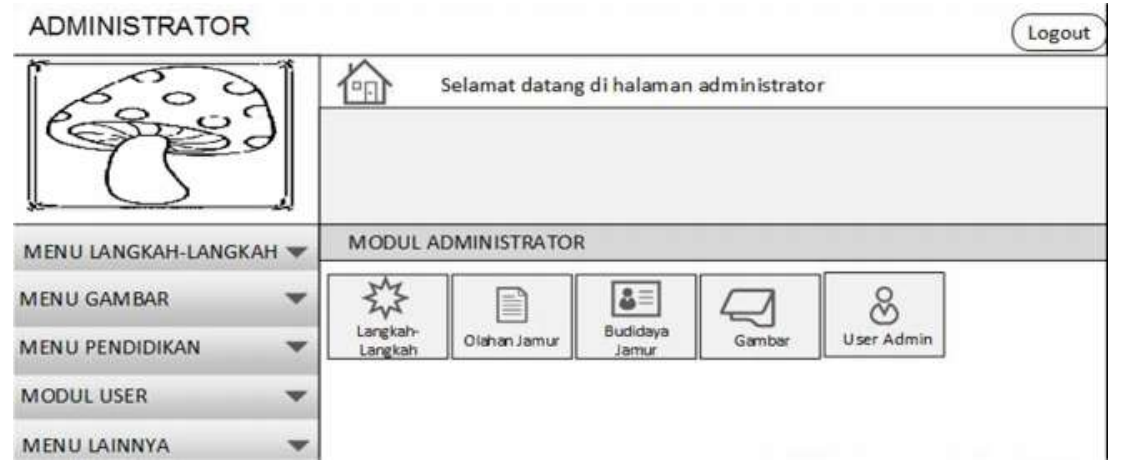

Gambar 8 Menu Utama

\section{b. Pilih Menu Langkah-Langkah}

Pada Gambar 9 merupakan tampilan menu dari menu langkah-langkah yang terdiri dari menu add langkah.

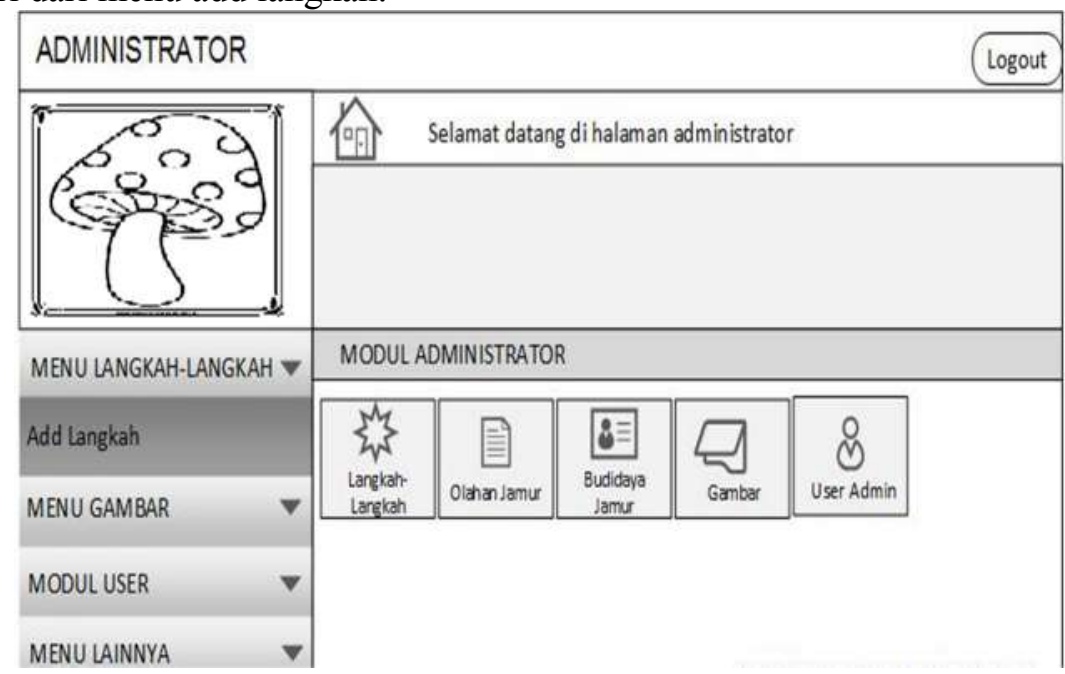

Gambar 9 Pilih Menu Langkah-Langkah

\section{c. Add Langkah}

Gambar 10 merupakan desain antar muka dari halaman menu dari langkahlangkah pembuatan baglog jamur tiram. Pada menu langkah-langkah pembuatan baglog jamur tiram ini akan menampilkan langkah-langkah pembuatan baglog jamur tersebut. 


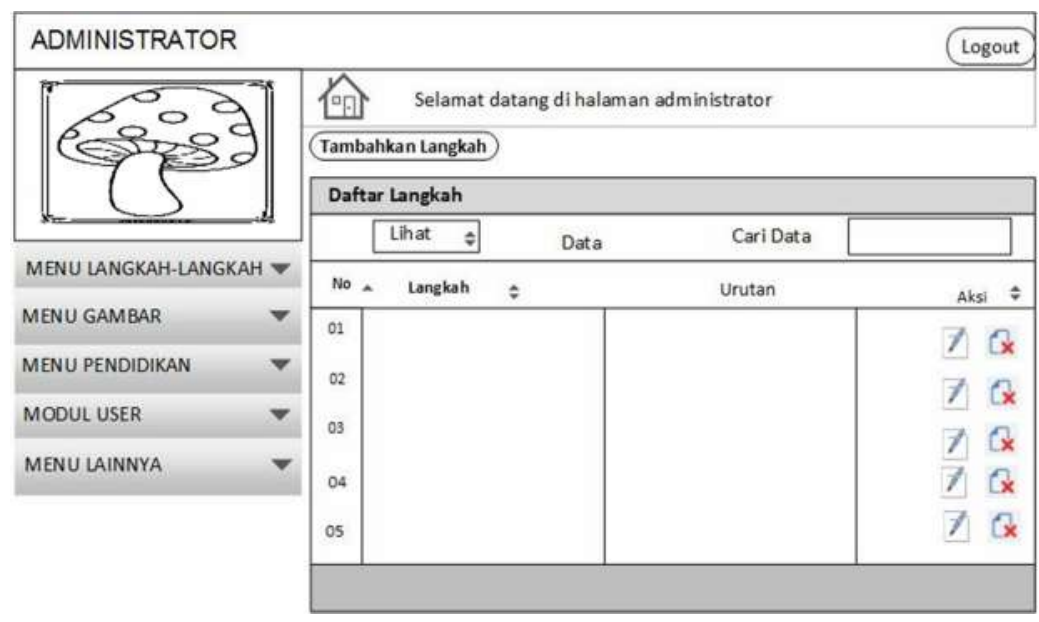

Gambar 10 Add Langkah

\section{d. Add Gambar}

Gambar 11 merupakan desain antar muka dari halaman menu dari gambar pembuatan baglog jamur tiram. Pada menu gambar pembuatan baglog jamur tiram ini akan menampilkan gambar pembuatan baglog jamur tersebut.

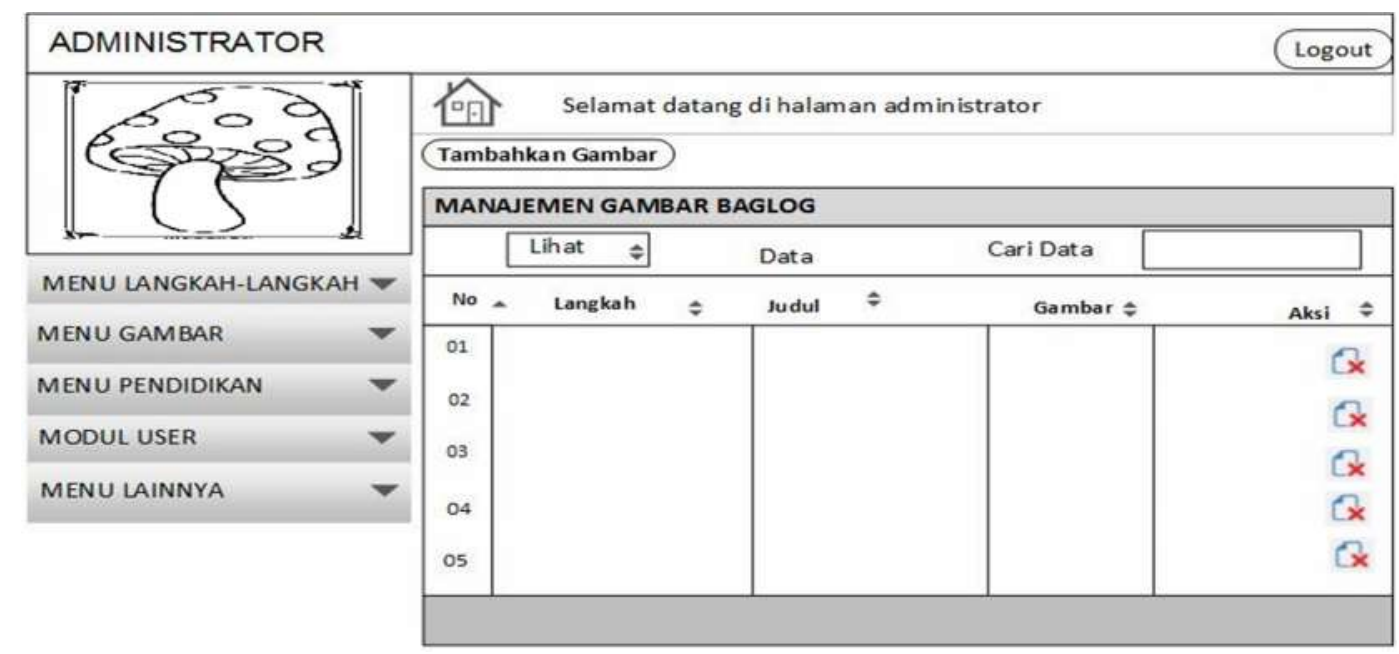

Gambar 11 Add Gambar

\section{KESIMPULAN}

Berdasarkan penelitian yang dilakukan, maka diperoleh kesimpulan sebagai berikut:

1. Penelitian ini telah menghasilkan suatu rancangan Aplikasi Notifikasi pembuatan baglog jamur tiram.

2. Rancangan system yang terdiri dari Unified Modeling Language (UML), Entity Relationship Diagram (ERD), Relasi Database, Struktur Tabel dan Desain Interface.

3. perancangan ini dapat membantu Developer dalam membangun Aplikasi Notifikasi pembuatan baglog jamur.

4. Aplikasi yang dirancang belum mengacu pada suatu platform tertentu, sehingga tampilan antarmuka (design interface) masih dapat dikembangkan lebih lanjut. 


\section{SARAN}

Beberapa hal yang dapat disarankan untuk menjadi bahan pertimbangan dalam penelitian selanjutnya, yaitu:

1. Agar penelitian ini dapat diimplementasikan menjadi system.

2. Mengingat perkembangan bahasa pemrograman dan development tools yang ada saat ini, maka sebaiknya dalam pengembangan aplikasi ini menggunakan bahasa pemrograman berorientasi objek.

3. Perlunya menambahkan lebih banyak atribut utama agar system dapat dipergunakan menjadi lebih baik dan mudah serta meningkatkan kwalitasnya.

\section{UCAPAN TERIMA KASIH}

Peneliti ucapkan terimakasih kepada pihak STIKOM Bali yang telah membiayai penelitian ini sehingga penelitian ini dapat diselesaikan.

\section{DAFTAR PUSTAKA}

[1] Triyono Untung Pribadi.2013. Bisnis Jamur Tiram. Jakarta Selatan : PT AgroMedia Pustaka

[2] Muad Asebag.2011. Pembibitan Jamur Tiram,Jamur Kuping dan Jamur Merang, Jakarta Selatan : PT AgroMedia Pustaka

[3] Yohana Ipuk Sunarmi.Cahyo Saparinto.2010. Usaha 6 Jenis Jamur Sekala Rumah Tangga. Depok : Penebar Swadaya 